\title{
Pierre Monbeig: a herança intelectual de um geógrafo
}

$A Z I Z A B^{\circ} S A B E R$

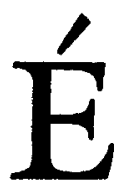

muito difícil falar de um mestre geógrafo que era admirado e venerado pela grande maioria de seus alunos. Mas seria indigno, para qualquer um de seus discípulos vivos, deixar de registrar a memória que tem de um professor diferenciado que marcou o destino cultural de toda uma geração. Éramos gente, predominantemente, de classe média baixa sofrida e empobrecida. No entanto, tínhamos grande orgulho e satisfaçáo íntima em alterar nosso cotidiano miserável com a alegria indiscutível de assistir às aulas e receber conselhos de uma legião de professores competentes, metódicos e atualizados com as circunstâncias de sua época. Dentre eles, destacava-se Pierre Monbeig, que permaneceu no Brasil, trabalhando na Faculdade de Filosofia, Ciências e Letras da recém-criada USP, por onze anos, do fim da década de 30 até a primeira década dos anos 40 (1935-1946).

Repito: difícil relembrar a figura do bom, seguro e inteligente mestre que adotou o Brasil como sua segunda pátria, até o fim de seus dias. Outros de seus discípulos culturalmente bem-sucedidos tiveram a mesma dificuldade. Caio Prado Júnior, por exemplo, escrevendo um rápido prefácio para um dos últimos livros de Monbeig sobre o Brasil, dizia: "Como amigo de Pierre Monbeig, e amigo de longa data, poderia dar-me por suspeito na apresentaçáo que dele faço - sinto-me, todavia inteiramente à vontade porque náo somente o conceito por ele granjeado no consenso geral dispensaria aquela minha apreciação, como porque se me liguei a Pierre Monbeig, foi precisamente atraído pelos seus invulgares dotes de homem da ciência que fazem tăo fecunda a convivência com ele" (setembro de 1957). Ás vésperas de completar meus $\mathbf{7 0}$ anos, não sei se terei tempo e tranqüilidade psicológica para escrever sobre Pierre Monbeig, Plínio Ayrosa, Aroldo de Azevedo, Jean Gagé, Roger Bastide, Emílio Willems, João Cruz Costa ou Aziz Simáo. Cada um deles que se foi, nos deixou ao traço amargo do vazio cultural e do amparo da amizade.

Existem poucos escritos sobre Pierre Monbeig: alguns referências formais em prefácios para seus diversos livros, uma nota substancial do jornal $O$ Estado de $S$. Paulo por ocasião de seu falecimento (setembro, 
1987) e uma excelente entrevista, publicada no mesmo órgáo da imprensa paulista, por Lourenço Dantas Mota e Antonio Carlos Pereira, em 4 de novembro de 1979. A releitura dessa entrevista, feita no momento da mais plena maturidade do velho professor e homem público francês, possibilita avaliar a trajetória de sua vida e a acuidade de suas idéias. Acrescenta-se a esse trabalho dos dois entrevistadores brasileiros, um artigo de Gilles Lapouge, especial para o Jornal da Tarde do dia 11 de fevereiro de 1984, em entrevista feita em Paris, na residência da família. Monbeig e D. Julieta viviam na capital francesa, em um apartamento alugado do Quartier Latin, pagando aluguel ao Papa, segundo comentou um dia. Ao longo de toda a sua vida, professor dedicado e pesquisador incansável, teve pouco tempo para obter um patrimônio pessoal. Espera-se que, em compensação, seus filhos tenham melhor sorte.

\section{A chegada ao Brasil para lecionar na Filosofia}

Pierre Monbeig veio ao Brasil para se agregar aos professores da missão francesa, convidada a participar da fundação da Universidade de São Paulo. Tinha, de saída, o difícil desafio de substituir um brilhante antecessor, que permanecera apenas alguns meses em São Paulo, transferindo-se depois para a Universidade do Brasil, no Rio de Janeiro. Efetivamente, o professor Pierre Deffontaines era uma personalidade aparentemente insubstituível. Dissidente da Sorbonne, mutilado de guerra, autor de livros de textos reconhecidos internacionalmente, Deffontaines havia tomado toda as iniciativas para implantar o ensino universitário das ciências geográficas em São Paulo e no Brasil. Coube a Monbeig, com sua tranqüilidade, sua linguagem cartesiana, e sua coerência de pesquisador e professor, dar continuidade plena e consolidar o trabalho iniciado por Deffontaines.

Havia um problema lingüístico a ser superado. Não era fácil chegar a um país da então distante e marginalizada América Latina, e, de pronto, aprender o português e ministrar aulas na língua local. Enquanto aprendia e se exercitava na fala do português, Monbeig ministrava todas as suas aulas em francês. Cabia à professora Maria da Conceição Vicente de Carvalho a tarefa de paralelizar e fazer acréscimos aos temas tratados. A maioria dos alunos aceitou a soluçáo encontrada e, certamente, beneficiou-se por ter tido a oportunidade de treinamento direto no terreno de uma segunda língua. Na época, quase toda a bibliografia nuclear da Geografia Humana era elaborada ou divulgada em francês. As próprias obras e idéias dos grandes mestres alemães e norteamericanos das ciências geográficas chegavam ao Brasil, via língua francesa. Artigos fundamentais sobre o nosso país, publicados na França, 
durante a guerra de 1939 a 1945, chegavam ao Brasil por via diplomática. Tal como aconteceu com o extraordinário trabalho de Emmanuel De Martonne, Problimes morphologiques du Brtsil tropical atlantique, trazido para o Rio de Janeiro, graças à iniciativa de Francis Ruellan, outro grande professor francês que colaborou com a implantaçáo da Geomorfologia na Faculdade de Filosofia da então Universidade do Brasil e com Conselho Nacional de Geografia do IBGE. Na ocasião, por essa e outras razōes culturais, todos nós ficamos devendo uma obrigação à parte a Pierre Monbeig, por nos ter permitido ingressar numa língua de importância universal para a ciência de uma época. Algo parecido

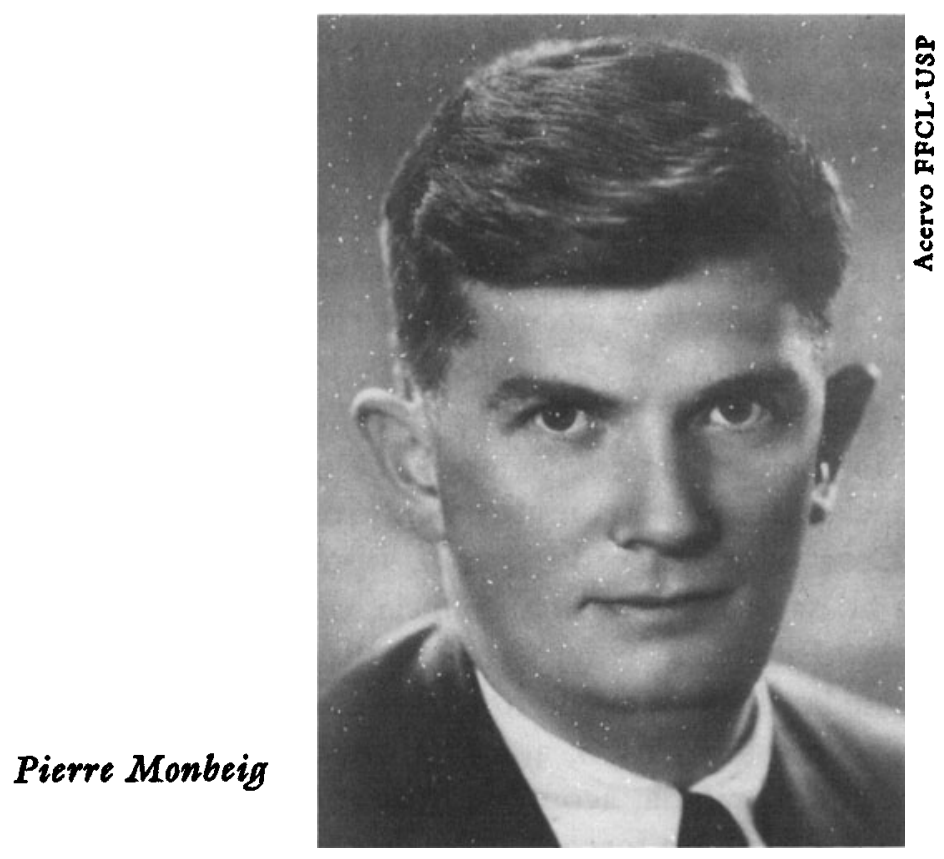

com o que acontece com o inglês neste fim de século e de milênio em nível da cultura científica internacional.

Monbeig era uma figura de jovem gaulês no ambiente da velha cidade de São Paulo de Piratininga. Na apreciação de Gilles Lapouge, em fevereiro de 1984, "Monbeig tem estatura média, veste-se com elegância em marrom-escuro, seu rosto é bastante esculpido, a tez rósea, brilhante e os cabelos de um branco cintilante”. Esta era, também, a nossa visão sobre o jovem professor que, então, ainda possúa cabelos menos brancos e uma vitalidade de fazer inveja aos seus jovens alunos. Lembro-me dele, a percorrer o longo corredor do terceiro andar da Escola Normal Caetano de Campos, transitando com rapidez pronun- 
ciada para chegar até a sala do canto, voltada para a praça da República e a rua Sete de Abril. Com o mesmo vigor que possuía ao ensejo das excursóes de campo, subindo ou descendo morros e chapadóes para obter um ponto de observaçáo mais aprofundado sobre a paisagem ou se achegar a algum homem do campo para uma entrevista dirigida, visando à compreensão da vida agrária regional.

A despeito de sua tranqüilidade habitual, Monbeig era uma pequena fera crítica perante a mediocridade de alunos, candidatos a alunos, ou escritos genéricos e epidérmicos, feitos por quem quer que fosse. Teve alguns aborrecimentos e constituiu desafetos graças ao seu atilado espírito crítico, às vezes explosivo. No entanto, de modo permanente e espontâneo, era capaz de refletir em voz alta, através de mensagens e conselhos do maior bom senso imaginável dirigidos a seus alunos, colegas ou eventuais visitantes culturais.

Nos vestibulares de 1941, o exame oral de Geografia foi conduzido por três examinadores, tendo ao centro a figura atenta de Pierre Monbeig. Nos primeiros anos da história da Faculdade houve uma estratégia destinada a receber professores do ensino secundário, em uma tentativa pontualizada de melhorar ou reclamar os conhecimentos geográficos dos mestres de escolas que já se encontravam na ativa. Nessa circunstância, Monbeig era muito mais jovem do que a maioria de seus alunos. Com o decorrer do tempo, optou pela juventude, e assim chegou a nossa vez. Nesta circunstância, os examinadores inquiriam os candidatos à Faculdade, com perguntas situadas muito acima do conhecimento médio dos jovens recém-egressos de cursos secundários. Monbeig era, ao mesmo tempo, atento e cáustico. Sua indignaçáo maior, ainda que muito rápida, acontecia quando percebia que alguns jovens vestibulandos náo liam jornais. Parte de sua nota final levava em consideração o fato de os postulantes à Universidade estarem em dia com a marcha dos acontecimentos políticos, sociais e econômicos do Brasil. Como decorrência desse critério adicional, os que possuíam apenas cultura livresca, baseada em obras didáticas incompletas e fragmentárias, sofriam com as questóes que lhes eram endereçadas.

Lembro-me bem: alguns de nós vindos do interior paulista, ainda conhecíamos quase nada da região de Sáo Paulo, onde estava se estruturando a grande Metrópole paulistana. Nesse sentido, a salvaçáo de alguns residia no aprendizado prévio, feito no chamado Colégio Universitário, no qual, por dois anos de estudos ocorria um intervalo de preparação para a Universidade. Outros, recém-saídos dos ginásios (com apenas cinco anos de estudos), tinham de se contentar com as aulas intensivas do cursinbo do Grêmio da Faculdade, que funcionava como exce- 
lente espaço de treinamento docente para os veteranos, em vésperas de formatura.

\section{As atividades extraclasse}

Terminados os exames: uma esperada lista dos resultados era afixada no centro do longo corredor Escola da Prafa. O medo de ter sido reprovado, decepçáo para alguns, alegria inusitada para os bem-sucedidos. Outra surpresa: uma pequena nota à margem da lista dos aprovados, convocando os calouros para um primeiro dia de aula... que deveria ser diretamente realizada no campo, através de uma excursão programada. Assinado: Pierre Monbeig, professor de Geografia Humana.

Foi através dessa iniciativa que a turma de 1941 foi introduzida ao conhecimento da paisagem e dos fatos cumulativos constituídos pela história dos grupos humanos e dos processos econômicos sobre o espaço geográfico. Nada de mais importante poderia ter marcado nosso destino, na escolha de uma ciência para ser cultivada pelo resto de nossas vidas, do que aquela primeira e predestinada excursáo sobre o terreno. A iniciativa era da inteira responsabilidade de Monbeig. O itinerário escolhido envolvia a saída a partir das colinas de Sáo Paulo e um transecto pelas serranias de Jundiaí, até atingir setores da chamada depressão periférica paulista. De Sáo Paulo a Jundiaí e a Campinas, até Salto e Itu, com regresso pelo famoso canyon do Tietê, passando por Cabreúva, Pirapora do Bom Jesus, Sant'Ana do Parnaíba e subúrbios ocidentais de São Paulo. Encantou-nos, sobretudo, a dinâmica dos caminhamentos e a acuidade das observaçóes de mestre Pierre Monbeig. Pelas suas mãos estávamos sendo iniciados na fascinante aventura cultural de compreender a organização antrópica imposta - com erros e acertos - à organização herdada da natureza. Fato que teve influência decisiva na escolha da profissão, no interior do curso de História e Geografia. Ficamos premidos por um duro dilema: ser geógrafos ou seguir a trilha, igualmente magnífica, dos estudos historiográficos. Alguns de nós resolveram a dura batalha interior seguindo o anastomosado caminho que envolve o cruzamento entre o espaço e tempo.

No antigo curso de Geografia e História da Faculdade de Filosofia solicitava-se muito dos alunos: todas as histórias; todas as geografias; língua portuguesa; princípios de Ciências Sociais; elementos de Cartografia; e, desenho. Era um vestibular para valer. Mas ao se ingressar no curso, propriamente, a tudo isso se acrescentava Antropologia Cultural, Etnografia e Tupi-guarani e Elementos de Geologia. Os exames de História eram menos drásticos, tanto no vestibular, quanto no decorrer do curso. Todos os professores nos forneciam uma cronologia seletiva dos 
fatos a serem detalhados e interpretados. Tratava-se de um procedimento que nos dava certa tranqüilidade, ainda que ilusória. Os trabalhos exigidos por quase todos os professores, para serem redigidos $\mathrm{em}$ um semestre, constituíam o ponto de nosso aprendizado, tanto no campo da História quanto, sobretudo, no da Geografia. De um lado, aprendiase a problemática dos contatos culturais e étnicos, em todas as suas consequiências. E, de outro, adentrava-se em conhecimento da estrutura dos terrenos, idade das formaçóes rochosas. A tarefa de separar a história geológica em fase da história geomorfológica e biogeográfica ficava por nossa conta e risco, obrigando-nos a realizar trabalhos extras, sem o controle ou a orientação de alguém.

Num esforço de memória, decorrido meio século em relaçăo ao tempo de atuaçáo de Monbeig na USP, tento me lembrar de alguns de seus conselhos extramuros da Faculdade. Restritos a leituras não muito sistemáticas, feitas na antiga Biblioteca Municipal da rua Sete de Abril e, posteriormente, na Biblioteca Mário de Andrade, alguns de nós tendíamos para teorizaçóes precoces. Monbeig nos alertava que toda a teorização precoce acabava por ser repetitiva e infértil. Era necessário iniciar-se por trabalhos analíticos sobre temas reais, percebidos no teatro geográfico das atividades humanas, quer no mundo rural quer no urbano. Antes de se iniciar nos trabalhos de campo e na percepção das relaçóes entre os homens e a terra, e os homens e a sociedade, era impossível teorizar. Foi um lembrete oportuno e definitivo para a formação de jovens geógrafos que um dia teriam de tratar das sérias e diferenciadas questōes regionais brasileiras, desde a Amazônia até os sertóes secos, as planícies costeiras e os planaltos interiores dominados por matas ou cerrados, bosques de araucárias e pradarias mistas. Locais onde a estrutura fundiária tendia a se enrijecer, o espaço geográfico tornava-se mercadoria, os trabalhadores rurais e urbanos eram tratados apenas como mão-de-obra braçal, sem direitos e sem proteção.

Fiel ao lema de introduzir seus alunos em tarefas de iniciaçáo, feitas diretamente no campo, Pierre Monbeig exigia deles estudos múltiplos sobre subáreas da região de São Paulo e de seus arredores. Ele sabia que nós, alunos egressos de classes pobres, náo tínhamos recursos para realizar pesquisas em áreas distantes, que exigissem despesas de viagens, estadia e transportes. Não existiam, na época, agências financiadoras para pesquisas; ele próprio tinha grandes dificuldades para dar continuidade às suas investigaçóes nas zonas pioneiras do Oeste Paulista $e$ Norte do Paraná. Monbeig nos pedia estudos da planície do Tietê, envolvendo formas e tendências da ocupação e uso dos espaços varzianos. Pouco mais tarde, Aroldo de Azevedo adotava a mesma estratégia, dividindo as tarefas dos seus alunos pelos mais variados setores da Gran- 
de Săo Paulo. Monbeig alternava suas exigências incitando-nos a ler os mais recentes artigos das poucas revistas especializadas disponíveis em Sáo Paulo. A fim de colocar-nos em dia com o cotidiano da vida paulista e brasileira incentivava-nos, através da leitura dos jornais, ao mesmo tempo em que chamava nossa atenção para percebermos conjunturas diferentes das açóes antrópicas sobre um só e mesmo espaço territorial. Ou seja, pensar os cenários de um setor qualquer do espaço geográfico, em épocas históricas diversas. Para tanto, mais tarde, tivemos que incorporar as brilhantes observações de Braudel sobre períodos de história longa e de história curta, envolvendo ciclos prolongados de rotina cumulativa e períodos rápidos de rupturas, envolvendo mudanças e destruiçóes irreversíveis. Nas ciências da Terra e da Ecologia - viemos a saber depois - as grandes mudanças fisiográficas e biogeográficas se processam, também, em períodos de transição tão rápidos quanto agressivos (teoria da biostasia e resistasia de Erhart). Curiosamente, Monbeig foi colega e grande amigo de Paul Braudel, através de uma permanente troca de idéias e conhecimentos. $\mathrm{E}$, mais tarde, quando de seu regresso à França, Monbeig trabalhou em Estrasburgo, na mesma universidade onde Enri Erhart elaborou suas teorias esclarecedoras sobre as consequiências pedológicas, morfológicas e fitogeográficas.

\section{Introduzindo seus alunos na geografia urbana}

Outro campo em que Pierre Monbeig conseguiu influenciar profundamente seus alunos foi o do terreno da geografia urbana. À medida em que foi tomando consciência sobre as cidades do interior paulista e norte-paranaense - nascidas e crescidas ao saber do ciclo do café Monbeig incentivou alunos e ex-alunos a realizarem monografias sobre os núcleos urbanos que melhor conheciam: ou, por terem neles nascido, ou porque neles desenvolveram atividades de ensino. Dessa sua iniciativa, surgiram vários estudos, mais tarde publicados em revistas, as mais diversas. Tínhamos uma vantagem em terrenos de épocas culturais dos anos 40 em São Paulo: recebemos os ensinamentos de Monbeig sobre as abordagens geográficas para estudar uma cidade e podíamos incorporar a elas os princípios e fundamentos criados pelos sociólogos da Escola de Chicago, introduzidos em boa hora por Donald Pearson em suas aulas e livros na Escola de Sociologia e Política. A fusão sobre esses dois feixes de metodologias foi um trabalho à parte, feito por nós mesmos, com grande enriquecimento para a compreensão da organização interna dos organismos urbanos. Mais recentemente, a tais conhecimentos elaborados ao longo de quase um século, acrescentou-se a abordagem ecológica interativa, simbolizada por estudos nos quais a cidade é entendida, também, como um ecossistema urbano dotado de complexo metabolizado. $O$ mais importante a salientar na avaliação 
dessas diferentes vertentes metodológicas é o fato de que elas não são excludentes. Pelo contrário, estas, e outras formas de entendimento dos fatos urbanológicos convergem para o entendimento mais holístico e dinâmico dos fatos do mundo urbano.

A justa preocupação de Monbeig com o estudo das cidades foi colocada em um trabalho pioneiro entre nós, publicado com o título de $O$ estudo geográfico das cidades (SP, Revista do Arquipo, 1941). O ponto alto desse artigo foi a introdução, no Brasil, dos conceitos de sítio urbano, posição geográfica e estrutura espacial das funçōes urbanas. Monbeig intentou, com extraordinária clarividência, acrescentar à metodologia sociológica e urbanística o ponto de vista geográfico. De um lado, recuperava as observaçóes pioneiras de Pierre Lavedan (França) e de Park e Burgess (Estados Unidos), incorporando todas as linhas de abordagem dos geógrafos norte-americanos e europeus que realizaram estudos sobre cidades em diversas partes do mundo, inclusive no Brasil (Preston James, Philipe Arbos, Deffontaines). Entretanto, Monbeig não se contentou com as observações iniciais que teceu sobre o estudo geográfico das cidades e, mais tarde, quando da reprodução do artigo no livro Nopos estudos de Geografia Humana Brasileira (Difusão Européia do Livro, 1957), acrescentou um apêndice incluindo novas informaçōes bibliográficas e um grande número de conselhos metodológicos, entranhados do maior bom senso, dignos da maior reflexão.

Nesse novo livro, editado após dez anos de seu regresso à França, Pierre Monbeig repetiu a façanha cultural de sua primeira coletânea de Ensaios. Com a mesma linguagem, versátil e quase coloquial, expôs seus pontos de vista sobre o Papel e valor do ensino da Geografia e de sua pesquisa e Os modos de pensar na Geografia Humana. Fez traduzir e reproduzir o trabalho pioneiro sobre As estruturas agrdrias da faixa pioneira paulista, assim como inseriu no livro seu meticuloso estudo sobre Aspectos geográficos do crescimento da cidade de Sáo Paulo, publicado originalmente em $O$ Estado de S. Paulo, de 25 de janeiro de 1954.

Nos seus cursos e seminários, bem preparados, Monbeig trazia para seus alunos o melhor das contribuições dos grandes geógrafos franceses de seu tempo: Vidal de La Blache, Albert Demangeon, Max Sorre, Emmanuel De Martonne, Jean Dresch. Introduziu-nos ao conhecimento dos grandes historiadores, dotados de boa formaçáo geográfica como Lucien Febvre, Marc Block e André Sigfried. Recuperou o melhor das contribuiçóes de Pierre Denis, Capot-Rey, J.J. Juglas, Pierre Deffontaines e do entáo jovem e genial Pierre George. Entre os norte-americanos, enfatizava a importância da obra Carl Sauer, Preston James e Clarence Jones. Através de pequenos informes ocasionais ficamos sabendo 
dos grandes dramas que atingiam a família dos geógrafos e historiadores: Marc Block, assassinado pelos nazistas nos arredores de Lyon: perda irreparável para a inteligência européia. Deffontaines e Capot-Rey, mutilados de guerra. Ou fatos como o grande e promissor geógrafo Pierre Denis, que tanto escrevera sobre a América do Sul, transformando-se em economista categorizado na Venezuela.

Homem de cultura, sem vaidades, Pierre Monbeig que tinha a obrigação moral de realizar uma carreira acadêmica na universidade francesa, retardou essa meta em favor de seus discípulos brasileiros. De pronto, passou a orientar alguns de seus melhores alunos, direta ou indiretamente, para o doutorado: Maria Conceição Vicente de Carvalho (Litoral Paulista), Nice Lecocq Müller (Sítios e sitiantes do estado de Săo Paulo), Ary França (A ilha de Sáo Sebastiáo), Renato da Silveira Mendes (Baixada Fluminense). Monbeig, além de seus discípulos mais antigos, tinha grande admiração pelo jovem geógrafo Pasquale Petrone, com muita razáo.

\section{A carreira acadêmica}

Antes de aceitar o convite para vir ao Brasil, Monbeig era professor iniciante em Caen, na Normandia. Tinha a idéia fixa de conseguir recursos para elaborar uma tese sobre as ilhas Baleares, na Espanha. Nunca negou, até o fim da vida, que sua opção pelo Brasil estava respaldada em obter recursos financeiros para poder subvencionar seu trabalho de tese de Estado, sobre as Baleares. Mas, aqui chegando, foi capturado pela temática de uma regiáo brasileira que se encontrava em pleno desenvolvimento rural e urbano, ainda que estivesse nos últimos estertores com relaçáo à monocultura cafeeira. Muito cedo, Monbeig descobriu a importância do tema das zonas pioneiras, as quais, no seu tempo, encontravam os seus limites de atuação no grande Oeste de São Paulo e no Norte do Paraná. Matas sendo suprimidas, vilas de apoio criadas, imigrantes chegando das mais variadas partes do mundo, ferrovias se estendendo com paradas de trens favorecendo a criação de importantes centros urbanos - futuras capitais regionais. Economia regional se dinamizando e se destacando no conjunto dos espaços produtivos do Brasil. Repercussóes do mundo rural e urbano no crescimento de uma grande cidade, candidata a metrópole. Industrialização se avolumando. Movimento cultural em pleno desdobramento: no jornalismo, no campo editorial, nas bibliotecas públicas, na vida universitária.

Comparado à França provincial, onde tudo estava consolidado e aparentemente já produzido, São Paulo era um espaço geográfico de múltipla dinâmica, que encantava os observadores alienígenas. Pierre Denis anotou os processos; Pierre Monbeig encantou-se pelo caráter 
autodesenvolvimentista de uma espaço privilegiado da América Tropical.

Assim, cedo (1937) abandonou o projeto de tese sobre as Baleares e partiu para a elaboração de sua grande pesquisa Planteurs et pionniers dans l'Etat de Saint Paulo, defendida na Sorbonne como Thise doctorat des Lettres, obtendo o prêmio de tese pela Fondation Nationale des Sciences (1950). Trabalho posteriormente editado pela Librarie Armand Colin, em 1952.

Muito embora seu trabalho de tese tenha tido sua redação terminada em França (Estrasburgo e Paris), as pesquisas do autor revelam uma trajetória de investigaçóes diretas de campo, pelas mais diversas regiốes de Săo Paulo, Paraná e Minas Gerais. E, ao mesmo tempo, um cuidado especial com a cartografia disponível e a documentação estatística adequada para respaldar os valores quantitativos referentes à regiáo em estudo. No prefácio de sua tese, Monbeig faz comentários precisos sobre a conjuntura da cartografia e da estatística durante o período de sua passagem por São Paulo (1935-1946).

Por anos, antes que houvesse um conjunto de revistas especializadas no Brasil e em São Paulo, os membros da missáo francesa da USP publicaram artigos e estudos prévios no tradicional jornal paulista $O$ Estado de S. Paulo, razáo pela qual a terceira página do referido periódico ficou famosa pela colaboração cultural freqüente de Roger Bastide, de Pierre Monbeig e de outros professores universitários. $O$ Estadão tornou-se, em São Paulo, o órgão de divulgação de ciências humanas; paralelizando o feito do Diário do Comércio do Rio de Janeiro, que havia possibilitado a divulgaçáo de estudos e artigos de grandes geólogos americanos que estiveram no Brasil no fim do século passado e início do século XX. A maior parte dos artigos de Monbeig sobre Sáo Paulo e zonas pioneiras do Centro-Sul brasileiro, publicados em $O$ Estado de $S$. Paulo foi posteriormente reproduzida em revistas e boletins geográficos especializados.

A sequiência dos estudos prévios do autor revela uma admirável atividade cultural: Les zones pionnières de l' Etat de São Paulo (Annales d'Histoire Economiques et Sociale, 1937); Algodão versus café (Geografia, A.G.B., 1936); Une nouvelle liaison entre São Paulo et Santos (Annales de Geographie, 1937); La population de l'Etat de São Paulo, Brésil (Annales de Geographie, 1937); Le voies de communication dans l'Etat de São Paulo (Bull, de l'Assoc. des Geogrs. Franf̧ais, 1937); The colonial nucleous of barão de Antonina, São Paulo (Geogr. Review, 1940); Algumas observaçóes sobre Marília, cidade pioneira (Rev. do Arq. Munic., SP, 1941); Comentários em torno do mapa de evolução 
da populaçăo do estado de São Paulo entre 1934 e 1940 (Geografia, A.G.B., 1934); Alta paulista e Alta araraquarense: duas regiōes novas paulistas (Boletim Geográfico, CNG/IBGE, 1946); A divisão regional do estado de São Paulo (Relatório Amual, 1946) (Anais da A.G.B., no 1, 1949); La croissance de la ville de São Paulo (Escrito em 1949), publicado em 1953 pelo Instituto de Geogr. Alpine, Grenoble); Les structures agraires dans la frange pionniere de São Paulo (Les Cabiers d'Outre Mer. Rep. de Geogr. de Bordeaux et de l'Atlantique, 1951); La ville de Saint Paul (Repue de Geogr. de Lyon, 1950).

Muito cedo, em 1940, Monbeig reuniu em um inspirado livro os estudos que fizera desde os primeiros meses de 1935, sob o título Ensaios de Geografia Humana Brasileira. Incluía no pequeno volume de ediçáo cômoda - pela Livraria Martins, a aula inaugural do curso de Geografia Humana ministrada na Faculdade de Filosofia: Que to Geografia? $O$ livro era dividido em seis partes principais: rumo a oeste, questóes paulista, a terra do cacau, varia, geografia e paisagem, e o movimento geográfico brasileiro. Para muitos, poderia parecer uma simples coletânea de estudos dispersos. Na realidade, era um esforço divulgar idéias fundamentais perante $o$ alunado $e$ as elites culturais paulistas. Em linguagem deliciosa, com espírito crítico atilado e vivacidade intelectual, realizou incursóes aos mais diversos setores da produção cultural. Tinha a capacidade de escrever com simplicidade e ao mesmo tempo penetrar na essência dos fatos. A releitura de dois excelentes textos do seu primeiro livro - Literatura e Geografia e $A$ paisagem espelbo de uma civilizagtio - documentam a originalidade de seu estilo e a modernidade de suas abordagens. Monbeig gebgrafo era certamente uma conseqüência de Monbeig intelectual.

\section{Mesmo de longe, o exemplo a ser seguido}

Em conselho que foi nos dado à distância, Monbeig investia contra o uso abusivo da expressáo ciencià aplicada, na qual cada grupo de especialistas procura uma aplicaçáo para sua área de conhecimento, sem levar em conta as fortes interaçóes necessárias para sua aplicabilidade. Em um congresso de cientistas franceses, Pierre Monbeig defendia a idéia de que existem aplicaçóes de ciências e não apenas um caso solista de aplicaçáo de uma ciência. Nessa ocasiāo, o mestre intuitivo que nele existia, procurava reorientar o pensamento de seus colegas para o campo da interdisciplinaridade indispensável às tarefas de aplicação de ciências a diferentes interesses da sociedade e do desenvolvimento econômico e social. Mal sabia Monbeig que estava provocando com para curta os seus vaidosos colegas, cada qual pretendendo encontrar aplicaçóes isoladas no campo científico a que se dedicavam. Hoje, após nossos 
próprios esforços no Brasil, sabemos que, somente combinadas, as ciências podem ter aplicação; e, ainda, se o conhecimento do receptor das propostas for suficientemente completo para que os conhecimentos interconexos possam ter resposta na sociedade. Do que decorre um fato de excepcional relevância: se não houver um esforço paralelo das ciências humanas para detectar defeitos da organização e do atendimento à sociedade, nenhuma ciência ou conjugaçáo de ciências pode ser útil e ética em sua pretensáo de aplicabilidade. Monbeig estava no caminho certo quando enfrentou seus colegas, deles recebendo o silêncio como resposta. Quem forjou parte dos seus conhecimentos no contexto do subdesenvolvimento tem mais força para entender a delicada problemática das aplicações de ciências.

$A z i z A b$ 'Sther, geógrafo, é presidente da Sociedade Brasileira para o Progresso da Ciência (SBPC) e professor honorário do IEA-USP. 